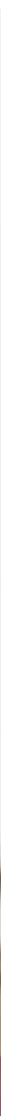

\title{
Engaging with UK Parliament on child and adolescent mental health research and policy
}

Researchers and expert practitioners can contribute to parliamentary work to inform policy-making. Sarah Bunn and Stephanie J Lewis describe why engaging with Parliament is important and explain how this can be done.

Have you ever wondered if UK Parliament is interested in research? Well, the answer is yes, very much so! The value of scientific discovery and expert evidence in policy-making has been brought into sharp focus in a very public way during the pandemic. COVID-19 research has been used in Parliament to inform debates, ministerial question times and select committee inquiries, improving the policy response. Although most parliamentarians do not have a research background, we've seen that they are all faced with the challenge of making decisions on issues about which research findings may be complex, incomplete or uncertain. It is therefore important that researchers and practitioners engage with Parliament and parliamentarians to highlight and help interpret nuanced evidence. This expert input enhances the use of research in parliamentary activities and can have real influence on the development of legislation, ultimately benefitting everyone. ${ }^{1}$ 
Parliament has recently focused a great deal of time and attention on the topic of mental health. For example, a quick search of UK parliamentary material in 2021 for "mental health" returns 4,626 individual results when the term was raised in parliamentary debates, questions, statements or reports. ${ }^{2}$ The number of UK parliamentary questions (PQs) including the term "mental health" has increased from 552 in 2012 to 1,408 (and counting) in 2021. ${ }^{2}$ While this may partly reflect an overall increase in the volume of $\mathrm{PQs}$, it illustrates that mental health is an issue that MPs and Peers regularly question Government about. To inform parliamentary work on mental health policy, researchers and practitioners can engage with Parliament in a number of ways, as individuals or as representatives of professional organisations. This article discusses these opportunities in UK Parliament. Similar processes may take place in other countries and specific information about this may be obtained through your institute's press office or impact team.

\section{Parliamentary Office of Science and Technology}

The Parliamentary Office of Science and Technology (POST, based in the UK Parliament) provides parliamentarians with accessible, impartial and trusted analysis of research to inform policy-making. To do this, POST consults experts who inform horizon scanning, identify research literature, and offer perspectives on how research relates to the policy context. Experts also help to peer review briefings and participate in events. To get involved, researchers and practitioners can sign up to POST's mailing list and respond to relevant aspects of POST's work programme. ${ }^{3}$

POST and research counterparts in the devolved parliaments also offer research fellowships, where talented individuals from across the research and practitioner communities come and work in Parliament for three months, usually to lead research work on parliamentary briefings, supported by parliamentary staff. For example, over recent years, four psychiatrists have joined POST for research fellowships, where they produced briefings on the age of criminal responsibility, ${ }^{4}$ and more recent work on the impact of the COVID-19 pandemic on the mental health of children, ${ }^{5}$ adults $^{6}$ and NHS staff. 7 POST will soon welcome a former social worker for a fellowship to lead a new briefing. There are openings for POST fellowships aimed at $\mathrm{PhD}$ candidates, ${ }^{8}$ and through the Academic Fellowship programme for those who are more established in their careers. ${ }^{9}$ These unique experiences provide fellows from various professional backgrounds with the opportunity to step away from their usual work and become immersed in a stimulating new environment, developing many useful skills to promote the use of research in policy-making.

Parliaments of many other countries have research services similar to POST. A useful list of these services can be found on the European Parliamentary Technology Assessment Network website. ${ }^{10}$

\section{Parliamentary Committees}

Committees are cross-party groups of backbench MPs or Peers, whose role is to hold Government to account, to challenge whether policies are working and to make recommendations on what Government might do better. ${ }^{11}$ Select Committees do this by holding inquiries, undertaking briefer pieces of work, and publishing reports, which the Government must respond to. For example, the Commons Health and Social Care Committee is currently undertaking an inquiry on children and young people's mental health, and the Joint Committee on Human Rights is scrutinising proposals for Mental Health Act reform. Committees on Bills analyse proposed legislation clause by clause, and make amendments that are then debated and further amended in Parliament. For example, the Health and Care Bill Committee is currently reviewing legislative proposals to reform the delivery and organisation of health services in England.

While undertaking this work, committees invite written and oral evidence from the public to inform their understanding of relevant issues, and they really value information that is submitted by researchers and practitioners. Select Committees also appoint external specialist advisors who are experts on the issues being assessed. Researchers and practitioners can find more information on Parliament's website about current select committee inquiries and the passage of Bills, as well as how to engage with committees. ${ }^{12}$ For devolved policy issues, including health and education, in Northern Ireland, Scotland and Wales, information is available online about engaging with committees and research services in the Northern Ireland Assembly, the Scottish Parliament and the Senedd Cymru. 


\section{Other engagement opportunities}

There are several other routes to engage with Parliament, ${ }^{1}$ for example by providing information to the Libraries of both Houses, and by contributing to one of the many all-party parliamentary groups that have interests in particular issues. Of course, researchers and practitioners can also connect with their local MP to highlight topics that are important to them and others in their area. Their MP's role is to represent constituents' interests when scrutinising Government through parliamentary debates, questions and committee work. As constituents, researchers and practitioners can therefore inform their MP's contribution to these policy processes.

If you would like to find out more about engaging with UK Parliament please get in touch. The Knowledge Exchange Unit would be delighted to hear from you! KEU@parliament.uk
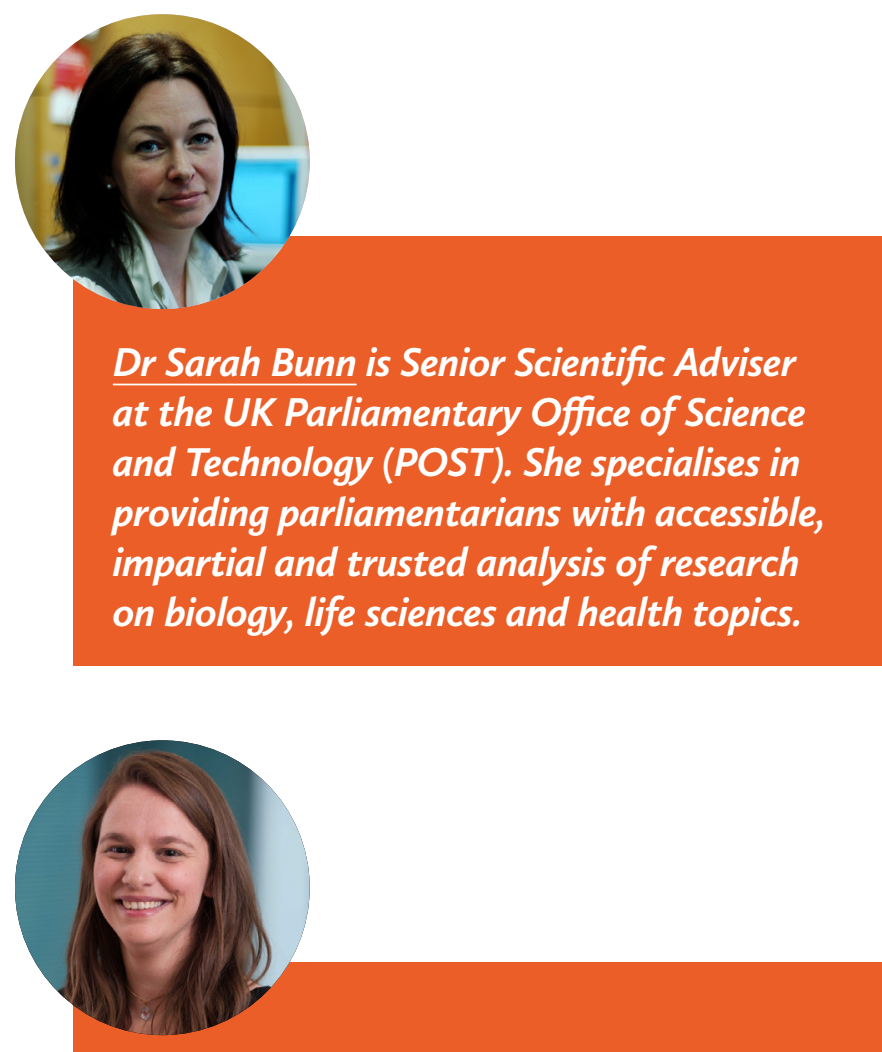

Dr Stephanie J Lewis is Clinical Lecturer in Child and Adolescent Psychiatry at the Institute of Psychiatry, Psychology and Neuroscience, King's College London, and is editor of the Bridge. She has recently undertaken a fellowship at POST, where she led a briefing on the impact of the COVID-19 pandemic on children's mental health.

\section{References:}

${ }^{1}$ UK Parliament (2021). Research impact at the UK Parliament

${ }^{2}$ UK Parliament (2021). Search parliamentary material [Accessed 8 Oct 2021]

${ }^{3}$ POST (2021). Work programme

${ }^{4}$ Brown P \& Bunn S (2018). Age of criminal responsibility. POST

${ }^{5}$ Lewis SJ \& Bunn S (2021). Children's mental health and the COVID-19 pandemic. POST

${ }^{6}$ Casanova Dias M \& Bunn S (2021). Mental health impacts of the COVID-19 pandemic on adults. POST

${ }^{7}$ Wilson C \& Bunn S (2020). Mental health impacts of COVID-19 on NHS staff. POST

${ }^{8}$ POST (2021). Fellowships

9 UK Parliament (2021). Academic fellowships

${ }^{10}$ EPTA (2021). Members

${ }^{11}$ UK Parliament (2021). Committees

${ }^{12}$ UK Parliament (2021). Parliament for researchers: how to work with select committees

To visit any of the links related to this article, click here to go to the ACAMH website.

: POST: Subscribe to POST

email alerts

湔 UK Parliament: Next steps and 'how

to' guides

滋 House of Commons Library:

Children and young people's mental health - policy, CAMHS services, funding and education 